\title{
Evaluation of Structural Element Weight of CSMIs via Hierarchical Entropy Analysis
}

\author{
Wang Yang, Sun Zhenjia
}

Beihang University, Beijing, 100191

Keywords: college students mass incidents (CSMIs); AHP method; entropy technology; evaluation index

\begin{abstract}
At present, college students mass incidents (hereinafter referred to as "CSMIs") is a hot topic of social concern, they will pose great threats to the safety and stability of universities and even the whole society once happened. To study the evolution mechanism and the control principle of CSMIs is important to the security and stability of college. This paper constructed the key structural element indicator system of CSMIs, and evaluated the index weight of each element by using hierarchical entropy analysis. The conclusions will be conducive to the further research on the generative mechanism of CSMIs, and further propose the effective control strategies for CSMIs.
\end{abstract}

\section{Introduction}

China is in the phase of transition, and the interactive influence of various deep social conflicts and the continuous adjustment of social patterns have contributed to the constant breakout of college students mass incidents (hereinafter referred to as "CSMIs"). According to the Blue Book of Chinese Society published by the Chinese Academy of Social Sciences, mass incidents led by Chinese college students have become a typical category of mass incidents and attracted a high degree of attention by the society. Most CSMIs are destructive to a certain degree, they will severely interrupt the normal education orderand pose great threats to the safety and stability of universities, and even to those of the whole society. Therefore, it is of practical significance to study the evolution mechanism of CSMIs.

CSMIs are a common type of mass incidents nowadays [1], classical research on social psychology abroad is all based on Western social settings, which believe in individual value that prioritizes individualism. While China is a typical country with collectivism and Chinese college students prioritize collectivism rather than individualism. Currently, domestic research on CSMIs is quite rare, but compared with mass incidents, CSMIs are often induced and participated by college students. Given that CSMIs happen in colleges, participants are characterized by a relatively higher knowledge level, the acute sense of politics and rights-safeguarding, younger age, and higher degree of external attention, thus CSMIs are of their unique characteristics. Tao Yingyong's definition of CSMIs [2] is relatively broad, covering the incidents caused by natural disasters such as earthquakes, typhoon, flood, fire and accidents, it is clearly stated that CSMIs happen in colleges and participants are college students. Guo Feng [3] believes that CSMIs bear the characteristics of misunderstandings, it should be emphasized that such incidents are caused by a certain incident and the rationality of college students demonstrated in the incident should be recognized. Pu Tianwei focuses more on the elements of CSMIs centered by the appealing of benefits and the concentration of hot topics, believing that "CSMIs are often referred to as incidents happening in colleges due to some shared attention, characterized by the participation of many students with organizational capacity. They can be quickly transformed into incidents with large scales and may possibly jeopardize the normal education order or social security". CSMIs mainly consist of frenzy disturbance; illegal gathering; collective sit-down, appealing, class boycott, meal boycott; demonstration; the disturbance of education and life order; gathering affray, and so on.

In this paper, it is believed that CSMIs are a typical category of mass incidents, they are referred to as those caused by unexpected cases with the participation of many students. They are characterized by organizational capacity and unexpectedness, and students in colleges gather either 
legally or illegally to express their appeals or opinions. CSMIs can be a powerful strength to promote the development of society, but can also be transformed into detrimental incidents that jeopardize the order and stability of colleges and society [4] [5]. The difference between CSMIs and common mass incidents is that the former belongs to the type of incidents led by elites [6] with the following features: the strong sense of group homogeny effect, the imbalance between the physical and mental development, the prominent expression of moods, the obvious influence of the internet, the high attention from society, and the interaction between domestic and international situations [7]. CSMIs are a double-edged sword; some domestic scholars tend to define them from the perspective of violence, anti-humanity, and negativity, believing that CSMIs will jeopardize normal education order and the stability of universities and may pose threat to society. While some scholars define CSMIs from the neutral or positive perspective, believing that CSMIs can serve as the valve for releasing social pressure, and can promote the development of society to a certain degree.

The successful evolution of CSMIs is the result of the interaction between different factors, namely, when different factors interact with each other, mass incidents may happen [8]. Analyzing the structural elements of mass incidents is of great importance to effectively control the evolution of mass incidents. Scholars both home and abroad have analyzed the structural elements of CSMIs, but most of the current research adopts qualitative analysis and structural elements can barely explain the influence indicator of the evolution of CSMIs in a systematic manner. Based on the above deficiencies, this paper constructs the indicator system of structural elements for CSMIs and evaluates the weight of indicators through hierarchical entropy analysis. Related conclusions are beneficial for further analyzing the evolution mechanism of CSMIs and provide reference for effectively controlling the evolution of CSMIs.

\section{Research Methods}

Current methods adopted for determining the weight of indicators include: analytic hierarchy process method, hierarchical entropy analysis method, entropy method, data envelopment analysis method, Sheffield method, and fuzzy weight method. This paper to determine the importance weight of structural elements of CSMIs using the hierarchical entropy analysis method, which combines the advantages of qualitative and quantitative methods and has been applied in many fields [9]. In this paper, the weight value of different structural elements is determined by analytic hierarchy process method, and the weights of structural elements are further corrected and tested via entropy method to gain the weight of indicators with more accuracy. The final weight values are comprehensively ordered to gain the evaluation result of importance.

\section{The Construction of the Indicator System}

On the basis of the analysis of the evolution of CSMIs and the model analysis of previous structural elements of CSMIs, this paper constructs an evaluation indicator system of structural elements of CSMIs according to the principle of comprehensiveness, systematization, hierarchy, and rationality of the structural element indicator evaluation system. The system is divided into four parts, which can be seen in Table 1. 
Table 1 The Evaluation Indicator System of Structural Elements for CSMIs

\begin{tabular}{|c|c|c|}
\hline $\begin{array}{l}\text { First level } \\
\text { indicator }\end{array}$ & $\begin{array}{l}\text { Second level } \\
\text { indicator }\end{array}$ & Third level indicator \\
\hline \multirow{4}{*}{$\begin{array}{l}\text { Participation } \\
\text { group }\end{array}$} & Group structure & $\begin{array}{l}\text { the structure of college participants, the structure of social } \\
\text { participants, leaders, participant relationship }\end{array}$ \\
\hline & Group emotion & $\begin{array}{l}\text { participants, leaders, participant reiaulonsnip } \\
\text { rage, anger, fear }\end{array}$ \\
\hline & $\begin{array}{l}\text { Group } \\
\text { motivation }\end{array}$ & $\begin{array}{l}\text { appeal for benefits, appeal for willingness, emotion release, the } \\
\text { blind following of the mass, the stand-by mentality, stimulation } \\
\text { from people nearby }\end{array}$ \\
\hline & Group scale & small-and-medium-sized scale, large scale \\
\hline \multirow[t]{2}{*}{$\begin{array}{l}\text { Unexpected } \\
\text { incidents }\end{array}$} & $\begin{array}{l}\text { External } \\
\text { environment } \\
\text { Internal } \\
\text { management }\end{array}$ & $\begin{array}{l}\text { political and economic problems of foreign countries, domestic } \\
\text { social problems, security conditions around universities } \\
\text { student service, university management, recruitment work, } \\
\text { accidental injuries and death of students, study press }\end{array}$ \\
\hline & Education level & $\begin{array}{l}\text { education quality, teacher qualifications, campus environment, } \\
\text { humanistic concern, university identification, career quality }\end{array}$ \\
\hline \multirow{4}{*}{$\begin{array}{l}\text { Information } \\
\text { spread }\end{array}$} & Spread channel & $\begin{array}{l}\text { the spread of human relationship, the spread of organization, the } \\
\text { spread of media }\end{array}$ \\
\hline & Source recipient & $\begin{array}{l}\text { strangers, classmates and friends, official organizations, internet, } \\
\text { TV and newspaper }\end{array}$ \\
\hline & $\begin{array}{l}\text { Information } \\
\text { release }\end{array}$ & $\begin{array}{l}\text { release channel, release content, release punctuality, release } \\
\text { accuracy }\end{array}$ \\
\hline & Rumor spread & rumor source, rumor content \\
\hline \multirow[b]{2}{*}{ Environment } & Time influence & specific date, specific time zone \\
\hline & Place influence & $\begin{array}{l}\text { population density, population movement degree, environment } \\
\text { nearby }\end{array}$ \\
\hline
\end{tabular}

\section{Evaluation of Indicator System}

Due to condition constraints, this paper chose 12 experts in related fields in colleges and one questionnaire was sent to each of them, 9 were collected. After analysis, 2 biased or invalid questionnaires were deducted. The weighted average calculation was conducted for the remaining 7 questionnaires, and the synthetic judgement matrix was formed, thus gaining the importance order of the structural elements for CSMIs.

Table 2 The Degree and Definition of Matrix Judgement

\begin{tabular}{cr}
\hline Degree & Definition and Explanation \\
\hline 1 & Between two elements, one is relatively more important than the other \\
5 & Between two elements, one is obviously more important than the other \\
7 & Between two elements, one is definitely more important than the other \\
9 & Between two elements, one is extremely more important than the other \\
$4 、 6 、 8$ & The degree of making a balance between the above mentioned two standards \\
\hline
\end{tabular}

(1) Structure judgment matrix. The feasible construction of judgment matrix is the key to hierarchical entropy analysis method. In $A=\left(a_{i j}\right)_{n \times n}$, the judgment matrix constructed in this paper, $a_{i j}$ is the value of the matrix for line $i$ row $j$, indicating the related importance of the $i$ th indicator to the $j$ th indicator. The matrix is determined by experts in related fields in colleges based on the importance degree of the structural elements indicator system, the value of the judgment matrix is determined according to Table 2. Finally a three level judgment matrix is constructed in this paper: $A, B_{1}-B_{4}, C_{11}-C_{42}, 18$ in total. 
(2) The determination of weight value. The weight values gained through hierarchical entropy analysis method are inducted as $p_{i j}=\frac{a_{i j}}{\sum_{i=1}^{n} a_{i j}}$ to get the matrix $p=\left[\begin{array}{cccc}p_{11} & p_{12} & \cdots & p_{1 n} \\ p_{21} & p_{22} & \cdots & p_{2 n} \\ \cdots & \cdots & \ddots & \cdots \\ p_{n 1} & p_{n 2} & \cdots & p_{n n}\end{array}\right]$, the values of different lines are added and induced as $m=\sum_{j=1}^{n} p_{i j}, \omega_{i}=\frac{m_{i}}{\sum_{j=1}^{n} m_{i}}, \omega=\left[\begin{array}{c}\omega_{1} \\ \omega_{2} \\ \vdots \\ \omega_{n}\end{array}\right]$, the weight values of different matrix are deducted.

(3) Entropy correction. In order to reduce the subjectivity in evaluation, entropy is used to correct the weight values gained using hierarchical entropy analysis method. The detailed steps are as follows: (1)all the values of the judgment matrix are induced to get the standard matrix $p=\left(p_{i j}\right)_{n \times n}$, in which $p_{i j}=\frac{a_{i j}}{\sum_{i=1}^{n} a_{i j}}$. (2)according to standard matrix $p$, the output entropy of $x_{j}$, the $j$ th indicator $e_{j}=-k\left[\sum_{i=1}^{n} p_{i j} \ln \left(p_{i j}\right)\right], k=\frac{1}{\ln n}$ is calculated; (3) the information weight values of the indicator $x_{j}$ are calculated: $u_{j}=\frac{g_{j}}{\sum_{j=1}^{n} g_{j}}, g_{i}=1-e_{j}$; (4) all the weight values of all indicators $\lambda_{i}=\left(\lambda_{1}, \lambda_{2}, \cdots, \lambda_{n}\right)^{T}$ are calculated using the formula $\lambda_{j}=\frac{u_{j} \omega_{j}}{\sum_{j=1}^{n} u_{j} \omega_{j}}$.

(4) Consistency test. The consistency indicator $C I$ and $C R$ are calculated using matrix $A=\left(a_{i j}\right)_{n \times n} . C I=\frac{t_{\max }-n}{n-1}, C R=\frac{C I}{R I}$, in which $t_{\max }=\sum_{i=1}^{n} \frac{(A \omega)_{i}}{n \omega_{i}}$ is the maximum characteristic root, $R I$ is the average random consistency indicator, the value of $R I$ is shown in Table 3 . If $C R<0.1$, then the judgment $A$ is of good consistency, if $C R \geq 0.1$, then judgment $A$ needs to be corrected until the consistency is achieved.

Table 3 The Value of RI, the average random consistency indicator

\begin{tabular}{|c|c|c|c|c|c|c|c|c|c|c|}
\hline$n$ & 1 & 2 & 3 & 4 & 5 & 6 & 7 & 8 & 9 & 10 \\
\hline$R I$ & 0 & 0 & 0.52 & 0.89 & 1.12 & 1.26 & 1.36 & 1.41 & 1.46 & 1.49 \\
\hline
\end{tabular}

The test result of matrix consistency is shown in Table 4. It can be seen that the matrix satisfies the condition of $C R<0.1$, thus it has passed the consistency test. 
Table4 Test result of matrix consistency

\begin{tabular}{ccccc}
\hline & $t_{\max }$ & $C I$ & $R I$ & $C R$ \\
\hline$A$ & 4.1969 & 0.0656 & 0.8900 & 0.0737 \\
$B_{1}$ & 4.0967 & 0.0322 & 0.8900 & 0.0362 \\
$B_{2}$ & 3.0399 & 0.0200 & 0.5200 & 0.0384 \\
$B_{3}$ & 4.2173 & 0.0724 & 0.8900 & 0.0814 \\
$B_{4}$ & 2.0000 & $-3 \times 10^{-6}$ & 0 & $-\infty$ \\
$C_{11}$ & 4.1969 & 0.0656 & 0.8900 & 0.0738 \\
$C_{12}$ & 3.0236 & 0.0118 & 0.5200 & 0.0227 \\
$C_{13}$ & 6.3870 & 0.0774 & 1.2600 & 0.0614 \\
$C_{14}$ & 2.0000 & $-1.9 \times 10^{-6}$ & 0 & $-\infty$ \\
$C_{21}$ & 3.0397 & 0.0198 & 0.5200 & 0.0382 \\
$C_{22}$ & 5.2391 & 0.0598 & 1.1200 & 0.0534 \\
$C_{23}$ & 6.2289 & 0.0458 & 1.2600 & 0.0363 \\
$C_{31}$ & 3.0001 & $3.03 \times 10^{-5}$ & 0.5200 & $5.8 \times 10^{-5}$ \\
$C_{32}$ & 4.2584 & 0.0861 & 0.8900 & 0.0968 \\
$C_{33}$ & 4.0925 & 0.0308 & 0.8900 & 0.0346 \\
$C_{34}$ & 2.0000 & $-4 \times 10^{-6}$ & 0 & $-\infty$ \\
$C_{41}$ & 2.0000 & $-3.7 \times 10^{-7}$ & 0 & $-\infty$ \\
$C_{42}$ & 3.0225 & 0.0113 & 0.5200 & 0.0217 \\
\hline
\end{tabular}

(5) The Order of importance. According to the calculation result above, the weight value of structural element indicator of CSMIs are shown in Table 5, the orders of importance of first level indicators are participation group, information spread, unexpected incidents, and environment, with their weigh values as $0.4072,0.3497,0.2082$, and 0.0349 respectively.

\section{Conclusion}

This paper constructed the structural element indicator system of CSMIs, and evaluated the index weight of each element by using hierarchical entropy analysis, the research shows that participation group, information spread and unexpected incidents take up most of the weight value in the structural element indicator system of CSMIs, in which (1) the single value of participation group reached 0.4072 and was the highest among all the indicators with the determining force; (2) the single value of information spread reached 0.3497, ranking the second and showed that information spread played as the catalyzer in the evolution of CSMIs under the circumstance of Internet use; (3) the single value of unexpected incidents reached 0.2082 , ranking the third and was the trigger for CSMIs; and (4) the weight value of environment was the lowest, but its function as the catalyzer for CSMIs was still obvious.

In conclusion, unexpected incidents, information spread and environment factors are the external driving force for CSMIs and the necessary factors, participation group is the internal driving force and the determining factor, and the combination of the internal and external forces contributes to the happening of CSMIs. The conclusions in this paper are conducive to understanding the importance degree and mutual function of different structural elements of CSMIs, and to providing reference for the effective control of the evolution of CSMIs. 
Table 5 Weight value of structural element

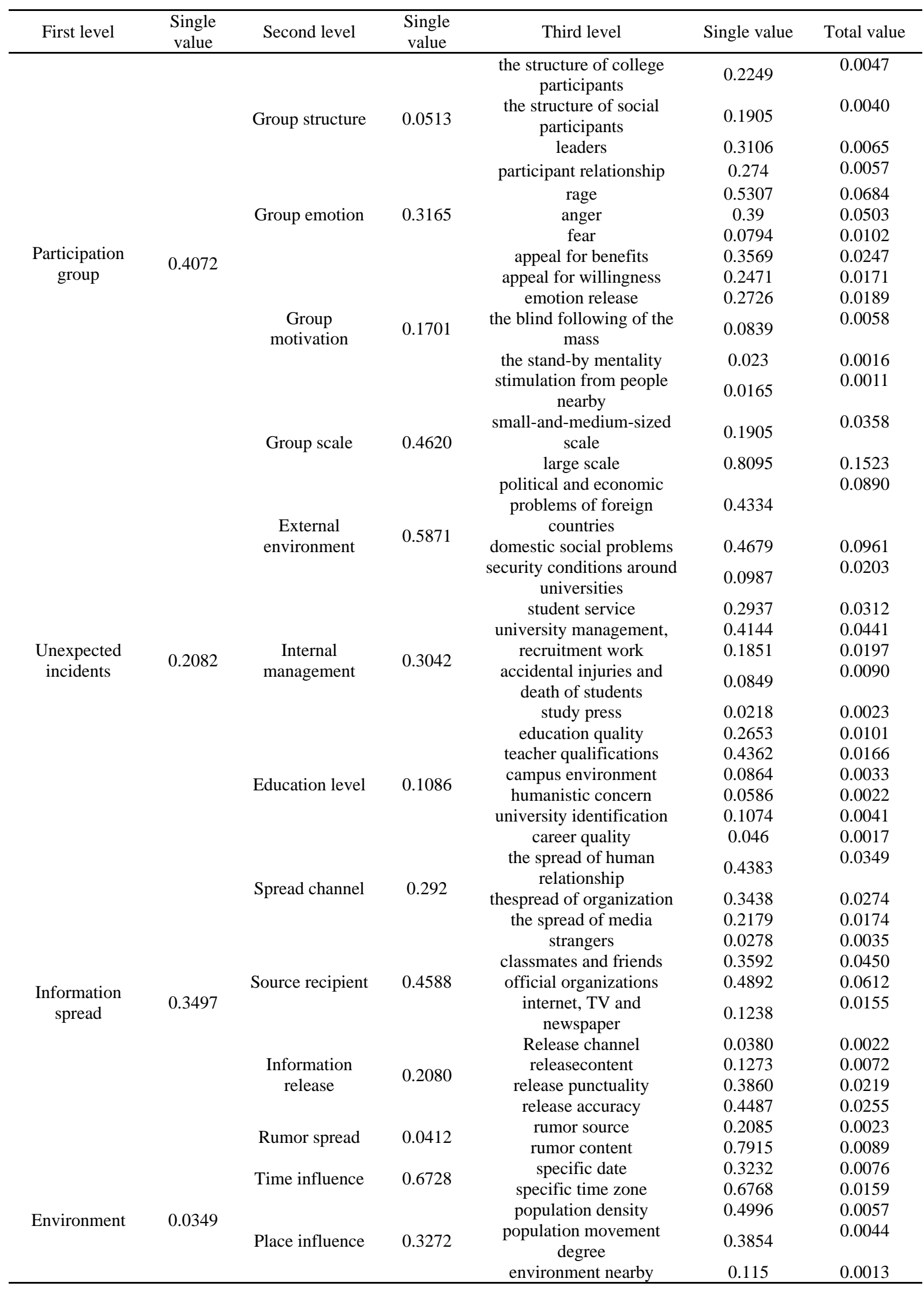

\section{References}

[1] ZHANG S. W., WANG E. P., ZHOU J.. The Motivation Mechanism of Collective Action in Different Contexts[J]. Acta Psychologica Sinica, 2012, 44(4): 524-545. 
[2] Tao Y. Y.. The Analysis and Tackling Strategies of the Contributing Factors of College Student Mass Incidents [J]. Journal of Henan Normal University, 2008, 35(4):215-217.

[3] Guo F.. A Study of the Turning Point of Crisis Management in University — Reflections on the Group Incidents of University Students [J]. Theory and Practice of Education, 2013, 21(33): 3-5

[4] Song, X. L..Research on College Student Mass Incidents from the Perspective of Game Theory [J]. Higher Agricultural Education, 2013, 11:91-95.

[5] Wang Y., Sun Z. J.. Study on Mass Emergency of Chinese College Students and Its Influence Factors[C]//Proceedings of The Twelfth International Conference on Industrial Management, 2014: 566-569

[6] Liu N. Explanation for Hatred, Construction of Participants and Rational Choice --- Analysis of the Possibility of the Emergence of Collective Activities in Central Regions in China [J]. Open Times, 2004(4): 57-701

[7] Yang X. Q.. Thoughts of the Tackling Strategies of College Student Mass Incidents [J]. Socialism Studies, 2006, 169(5): 115-117.

[8] Wang Y., Sun Z. J.. Study on Mass Emergency of Chinese College Students and its Influence Factors[C]//Proceedings of The Twelfth International Conference on Industrial Management, 2014: 566-569.

[9] Yang L. Liu C. C. Song L.. Evaluation of Coal Mine Emergency Rescue Capability Based on Entropy Weight Method [J].China Soft Science, 2013, (11):185-192. 